Uroš Lajovic

\section{Revision report}

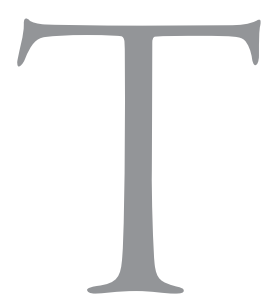

he annotations and remarks in the revision report refer to the differences between the score of the autograph of Sixth Symphony - 'Pastoral' by Ludwig von Beethoven (Beethoven-Haus Bonn, $\mathrm{BH} 64)^{\mathrm{I}}$ and the second transcript of the score by Beethoven's copyist Joseph Klumpar, kept by the National and University Library NUK in Ljubljana (NUK, Glasbena

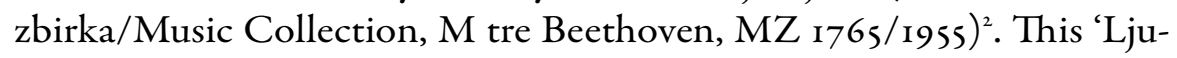
bljana' transcript could, in analytical comparison with the first authorised transcript of the score (also by the copyist Klumpar) kept by the Beethoven House in Bonn (Beethoven-Haus Bonn, NE I46) 3 be characterised as a 'clean copy', since all the corrections entered in the first transcript by Beethoven have been considered in the Ljubljana transcript. There is a particular value to the Ljubljana transcript in Beethoven's additional remarks.

I Accessible at: Beethoven-Haus Bonn, https://www.beethoven.de/de/digitales-archiv. (Accessed on I May 2019).

2 Accessible at: Beethoven, Ludwig van (I808). Sinfonia pastorale. URN:NBN:SI:DOC-98LTR6Yo, http://www.dlib.si.

3 Beethoven-Haus Bonn.
The revision report pays attention almost exclusively to the accidences, ${ }^{4}$ where the biggest differences appear. However, also mentioned are other particularities in which the 'Ljubljana' transcript varies from the autograph, the first transcript, and the contemporary editions. The places where accidences appear in the form of wedges, and are the same in all editions, are not included in the revision report.

\section{Abbreviations and marks}

Abbreviation

Mark

\begin{tabular}{cc}
\hline Bar & $\mathrm{b}$. \\
\hline Bassoon & $\mathrm{fg}$ \\
\hline Cello & $\mathrm{vlc}$ \\
\hline Clarinet & $\mathrm{cl}$ \\
\hline Contrabass & $\mathrm{cb}$ \\
\hline
\end{tabular}

4 The term 'accidence' is not being used here in the narrow musical-theoretical meaning, but marks all characters and other semantic signs that interpretatively define a note more precisely. 


\begin{tabular}{|c|c|c|c|c|}
\hline & Abbreviation & Mark & Abbreviation & Mark \\
\hline & Flute & $\mathrm{fl}$ & sforzato & sf \\
\hline & forte, fortissimo & $f, \mathrm{ff}$ & Timpani & timp \\
\hline & Horn & cor & Trumpet & $\operatorname{tr}$ \\
\hline & Oboe & $\mathrm{ob}$ & Viola & vla \\
\hline & piano, pianissimo & $\mathrm{p}, \mathrm{pp}$ & Violin I. or II. & vni I., vni II. \\
\hline $\mathbf{I}^{\text {st }} \mathrm{mov}$ & ement & & & \\
\hline Bar & Autogr & Haus Bonn, BH 64 & $2^{\text {nd }}$ transcript, 1 & $M Z_{1765 / 1955}$ \\
\hline I & Final note in th & & Final note in the bar equ & lge. \\
\hline 5 & $\begin{array}{l}\text { Vni II. have the } \\
\text { likewise with V }\end{array}$ & next bar, & Same. & \\
\hline 12 & Vni I. note with & & Same. & \\
\hline I5 & Vla dots. & & First note dot, second on & \\
\hline $16-19$ & Vni I. dot uncle & first note, onward dots. & Undoubtedly wedges. & \\
\hline & Vni II., vla dots. & & Wedges. & \\
\hline $19-27$ & Vni I. from here & end of phrase. & Same. & \\
\hline 33 & $\mathrm{Cl}$, fg dots until & & Same. & \\
\hline 37 & Vni I. wedges, e & & Dots in all instruments. & \\
\hline $4 \mathrm{I}$ & $\begin{array}{l}\text { Dots in all instr } \\
\text { unequivocally it } \\
\text { in b. } 45 \text {. }\end{array}$ & $\begin{array}{l}\text { beat (not entirely } \\
\text { ed in all the instruments }\end{array}$ & Same. & \\
\hline
\end{tabular}




\begin{tabular}{|c|c|c|}
\hline Bar & Autograph [18○8], Beethoven-Haus Bonn, BH 64 & $2^{\text {nd }}$ transcript, Ljubljana, NUK, MZ $1765 / 1955$ \\
\hline 42 & $\mathrm{Ob}$ (mistakenly) arc only across the semiquavers. & Same. \\
\hline $54-65$ & Vni I. wedges. & Dots. \\
\hline 66 & Vni I. dots only in this bar. Vlc wedge. ${ }^{6}$ & Dots. \\
\hline 108 & In winds, undoubtedly dots. & Same. \\
\hline II6-127 & Vni I., vni II. wedges all the time. & Dots at start, after page break, wedges. \\
\hline I3I-I35 & Vla undoubtedly dots, Vlc wedges. & Vla, vlc wedges. \\
\hline $135-137$ & Vni I., unclear, most likely dots. & Wedges. \\
\hline I88 & Vni I., fg no accidences! ${ }^{7}$ & Wedges. \\
\hline $191-192$ & Vni I., fg dots. & In vni I. dots, in fg wedges. \\
\hline 193 & $\begin{array}{l}\text { Vni II. second beat without accidences, } \\
\text { vlc in analogue bar } 195 \text { dots. }\end{array}$ & Same. \\
\hline $197-213$ & $\begin{array}{l}\text { Vni I. dots, from b. } 213 \text { onward wedges. } \\
\text { Vni II. and ob already have wedges from bar } 201 \text { on. }\end{array}$ & Dots. \\
\hline 234 & Same as in b. $\mathrm{I} 88 \mathrm{fg}$ and vni I. without accidences. & Wedges. \\
\hline 237 & Vni I. for a change from before (b. I9I) now wedges. & Vni I. and fg dots, after page break, wedges. \\
\hline 240 & Vni II. have dots notated this time, Vlc in analogue b. 242 dots. & Same. \\
\hline 246 & Fl dot on the first beat. & Nothing. \\
\hline 250 & Vla, Vlc dot; same in bar 254. & Wedges. \\
\hline 258 & Vni I. dot; same later in b. 262 (cum grano salis). & Dots (the same). \\
\hline 266 & Wedges in winds, dots in strings, also later. & Wedges, later dots all the time. \\
\hline
\end{tabular}

6 By notating dots instead of wedges in the last bar, Beethoven surely wishes to soften the play before the next passage under the arc.

7 Another crossing into softer play. It needs to be pointed out that, in the authorised score, the accidences are notated and are not corrected in this bar. Contemporary scores follow the first transcript and notate the accidences per analogiam. 


\begin{tabular}{|c|c|c|}
\hline 275 & Dots, written obliquely. & Wedges. \\
\hline 284 & Trill ends in double Nachschlag, corrected later. & Same. \\
\hline 285 & In my opinion, dots. ${ }^{8}$ & More likely dots. \\
\hline $29 \mathrm{I}$ & Dots. & Wedges. \\
\hline 297 & A dot. & A wedge. \\
\hline $300-303$ & Undoubtedly dots. & More likely wedges. \\
\hline $304-308$ & Vla dots, gradually changing into wedges. ${ }^{9}$ & Wedges (cum grano salis). \\
\hline 308 & In basses wedges, in vla dots. & In basses dots, in vla wedges - just the opposite. ${ }^{10}$ \\
\hline 312 & Despite ff dots. & Same also onward. \\
\hline 316 & Different than b. 4I, this time wedges. & Dots. \\
\hline $34 \mathrm{I}$ & This could be dots, but are more wedges. & Not entirely undoubted dots. \\
\hline 422 & Wedges. & More likely dots. \\
\hline 492 & Mixed; more likely wedges. & Undoubtedly dots. \\
\hline
\end{tabular}

8 Dots and 'staccato' redouble as interpretative instruction; therefore, I consider dots as accidences an expression of line importance.

9 Dynamics considered $(p p)$, they can be regarded as dots.

Io Compared to the note picture vla in b. 305, wedges in basses can be considered dots. 
In this movement, there are caesuras marked in bars 33 and 40 , and

The copyist had likely used them to mark page breaks; therefore, they again in bars Ios and II3, but they are not written in Beethoven's pencil.

naturally cannot be admitted.

\section{Bar $\quad$ Autograph [1808], Beethoven-Haus Bonn, BH 64}

Start In the autograph and the first transcript, there is still no remark of two Vlc 'solo Con sordino'.

23 One of the rare corrections by Beethoven in the autograph. In the vla part, a line was mistakenly written a third too low on the third beat, and the error corrected in red pencil.

32 Vni I. dots noted on the second beat above the semiquavers. The notation is given on the bottom system.

\begin{tabular}{|lll}
\hline $33-37$ & Vni II. trills with Nachschlag. ${ }^{13}$ & Vni II. trills without Nachschlag. ${ }^{14}$ \\
\hline 45 & Vni I. dots, but distinctive wedges in the next bar. ${ }^{15}$ & Mixed - dots and wedges. $^{16}$ \\
54 & No accidences. & $\begin{array}{l}\text { First notated dots were changed to wedges by Beethoven } \\
\text { in red pencil. }\end{array}$ \\
\hline 58 & Fl dots! & Same. \\
\hline 65 & Winds wedges. & Dots. \\
69 & Vla dots! & Same. \\
76 & Fg accidences read as dots. & Same. \\
\hline
\end{tabular}

\section{$2^{\text {nd }}$ transcript, Ljubljana, NUK, MZ 1765/1955}

A crabbed remark ' $[D]$ ue Violoncelli' and under it '[Pri] mo e secondo solo Con Sordino."

Transcribed correctly by the copyist.

$$
\text { Wedges. }{ }^{12}
$$

(Weses.

Bottom margin of the page is clipped quick, the text is partially cut-off and very difficult to read (' $[\mathrm{g}]$ li Violoncelli tutti coi Bassi').

12 They were likely also perceived as such by Beethoven, who had not intervened on this spot, but changed dots to wedges in the analogue $54^{\text {th }}$ bar.

I3 Beethoven had explicitly stressed such play in his remark below on this page, since he had run out of space in the system because of corrections.

I4 Copyist had likely not noticed Beethoven's remark.

I5 This spots needs to be unified.

16 The principle cannot be established. 


\begin{tabular}{|c|c|c|}
\hline Bar & Autograph [18०8], Beethoven-Haus Bonn, BH 64 & $2^{\text {nd }}$ transcript, Ljubljana, NUK, MZ $1765 / 1955$ \\
\hline 87 & Last trill note is without Nachschlag! & Same. ${ }^{17}$ \\
\hline $9 \mathrm{I}$ & $\begin{array}{l}\text { Ob all quavers equipped with dots. } \\
\text { Vni I. no accidences. }\end{array}$ & $\begin{array}{l}\text { Without accidences. } \\
\text { Vni I. same. }\end{array}$ \\
\hline $9 \mathrm{I}-94$ & & $\begin{array}{l}\text { On bottom margin, flute line is written-in an octave lower } \\
\text { in the last system. This is not a correction, but merely } \\
\text { an instruction to the copyist for easier identification of the flute } \\
\text { part, that has to be written with auxiliary lines in third octave. }\end{array}$ \\
\hline $\mathrm{IO4}$ & Vni I. there is no ligature on the first beat. & Same. \\
\hline IO8 & $\begin{array}{l}\text { Vni II. trills no longer have Nachschlag on the last beat, } \\
\text { but they can be perceived per analogiam. }\end{array}$ & Same. \\
\hline II7-II 8 & Vni I. in both bars, characteristic wedges. & Fg, vni I., in b. 2 also $\mathrm{fl}$ and $\mathrm{cl}$, dots. \\
\hline
\end{tabular}

\section{$3^{\text {rd }}$ movement}

\begin{tabular}{|c|c|c|}
\hline Bar & Autograph [1808], Beethoven-Haus Bonn, BH 64 & $2^{\text {nd }}$ transcript, Ljubljana, NUK, MZ $1765 / 1955$ \\
\hline I & Dots. & Same. \\
\hline 4 & Vlc dots. & Vlc dots, later corrected to wedges. Same in b. 4I2. \\
\hline $33-39$ & $\begin{array}{l}\text { All instruments dots. } \\
\text { In the parts ob, fg dots are later added in red pencil } \\
\text { (exception of two notes in } \mathrm{fg} \text { ). }\end{array}$ & All instruments dots. \\
\hline 53 & In $f f$ wedges are notated, except in vla where there are dots. & Dots. \\
\hline $9 \mathrm{I}$ & $\begin{array}{l}\text { Ob have dots judging by Beethoven's writing; on repetition } \\
\text { in b. } 99 \text { more likely wedges. }\end{array}$ & $\begin{array}{l}\text { In the first bar dots, in the second wedge. On repetition } \\
\text { in b. } 99 \text { wedges in both bars. }\end{array}$ \\
\hline 133 & Cor more likely wedges. & Without accidences. \\
\hline
\end{tabular}

17 Copyist notated the last trill note with Nachschlag; he had likely overlooked the detail and wrote it automatically. 
I65 Vni I. accidences not unequivocal; according to dynamics, wedges.

Same.

197 Basses wedges. On repetition in b. 40I nothing.

Same. On repetition in b. 4 or wedges.

439 Only vni I. line is indicated in the autograph.

\section{$4^{\text {th }}$ movement}

\begin{tabular}{|c|c|c|}
\hline Bar & Autograph [18०8], Beethoven-Haus Bonn, BH 64 & $2^{\text {nd }}$ transcript, Ljubljana, NUK, MZ $1765 / 1955$ \\
\hline 3 & Vni II. undoubtedly dots. & No accidences. \\
\hline 5 & Vni I. in two bars tied notes, onward dots. & No ligature or accidences. ${ }^{18}$ \\
\hline 8 & Vla dots. & Same. \\
\hline I5 & Vn I. again ligatures in two bars. & Same. \\
\hline I8 & Vla dots & Same. \\
\hline $2 \mathrm{I}-32$ & Vlc and cb quintuples. & Vlc quintuples, cb quadruples. \\
\hline 33 & $\begin{array}{l}\text { Vni I.: initially, only both semiquavers were tied. Later, arc } \\
\text { is only stretched to the quaver. A dot is noted above the quaver. }\end{array}$ & $\begin{array}{l}\text { Ligature every time over the entire motif pass. A dot is noted } \\
\text { above the quaver. }\end{array}$ \\
\hline $4 \mathrm{I}$ & $\mathrm{Cb}$ : dynamic mark missing, other instruments $p p$. & all instruments $p$. \\
\hline 43 & Basses $f$. & Basses sf. \\
\hline 47 & Basses without dynamic mark. ${ }^{19}$ & Basses sf. \\
\hline 56 & Vni I. not entirely unequivocal dots. & Dots. \\
\hline
\end{tabular}

8 In the authorised score that had been written earlier, ligatures are present.

I9 Because of this, it is also clear why, in the next phrase (bar 49) there is no dynamic mark (because dynamics remain $p p$ ). 


\begin{tabular}{|c|c|c|}
\hline Bar & Autograph [18॰8], Beethoven-Haus Bonn, BH 64 & $2^{\text {nd }}$ transcript, Ljubljana, NUK, MZ ${ }_{1765 / 1955}$ \\
\hline 26 & $\begin{array}{l}\text { Vla and vlc arc over all three notes, in spite of this wedge } \\
\text { above the last note. }\end{array}$ & Same. \\
\hline 30 & Vla and vlc wedge above the last note. & Same. \\
\hline 63 & Vni I. dots in the entire passage. & Same. \\
\hline $78-79$ & $\begin{array}{l}\text { Wedges in all of the orchestra, in tr even written-in } \\
\text { by another hand. }\end{array}$ & Same, even though dots are sometimes notated. ${ }^{\circ}$ \\
\hline $8 \mathrm{I}$ & Wedges on the last beat. & Vni I. dot, Bassi wedge, $\mathrm{fl}$ and ob without accidences. \\
\hline 99 & Vni II. in $p$ only dots; same in b. IO3. & Vln II. wedges after two tied notes. \\
\hline IOI-IO6 & $\begin{array}{l}\text { Vni I. in } f \text { dots in notes tied in twos, and on the second beat dots } \\
\text { only above two notes above } s f \text {; last four notes are always without } \\
\text { accidences. }\end{array}$ & $\begin{array}{l}\text { Vni I., vni II. After a ligature on ist beat dots, and on } 2^{\text {nd }} \text { beat } \\
\text { above } s f \text { two semiquavers equipped with wedges; the rest } \\
\text { of the notes in this bar have dots again, then no more. }\end{array}$ \\
\hline 125 & $\begin{array}{l}\text { Vni I. first note distinctive wedge, others not; along it the remark } \\
\text { 'staccato'. }{ }^{21}\end{array}$ & Dots and remark 'staccato'. \\
\hline $182-185$ & $\begin{array}{l}\text { Vlc: in crescendo dots at first, then wedges in an ever stronger } \\
\text { dynamics. }\end{array}$ & $\begin{array}{l}\text { Throughout the passus, following one another are dots } \\
\text { in the first, and wedges in the second bar over every two bars. }\end{array}$ \\
\hline 245 & The entire ensemble second and third note wedges. & Dots. \\
\hline 254 & Basses along wedges also remark 'staccato'.22 & Same. \\
\hline
\end{tabular}

20 Dots may be perceived as wrong notation.

2I Both remarks redouble, meaning that staccato refers to the technical side of performance, and wedges to the passage importance content-wise.

22 See remark above in b. I25. 